Resumo Expandido

\title{
Seminoma em equino: relato de caso
}

\section{Marcus André Ferreira Sá}

Docente do Curso de Medicina Veterinária do Centro Universitário de Barra Mansa - UBM, Doutorando PPGMV/UFRRJ.

\section{Hellen Magela Barreto}

Discente do Curso de Medicina Veterinária do Centro Universitário de Barra Mansa - UBM

\section{Corrine Fraga de Andrade}

Discente do Curso de Medicina Veterinária do Centro Universitário de Barra Mansa - UBM

\section{Júlio César Ferraz Jacob}

Doutor, Docente DRAA/IZ/UFRRJ

\section{Natália de Figueiredo}

Discente do Curso de Medicina Veterinária do da Universidade Federal Rural do Rio de Janeiro - UFRRJ 


\section{Introdução}

Os seminomas são comuns em garanhões idosos e, ao contrário do homem e do cão, não tem nenhuma correlação com criptorquidismo, podendo ser uni ou bilateral (SOUSA et al., 2017). Segundo Beck et al. (2001), estes tumores surgem das células germinativas do epitélio testicular espermático, ocorrendo principalmente em testículos retidos na cavidade abdominal de animais adultos os mais velhos, sendo considerados benignos. Também podem ser únicos, múltiplos, unilaterais, bilaterais ou císticos.

Os sinais clínicos incluem: dor abdominal e local, anorexia, letargia, vômitos, disúria, disfunção de marcha e hipertermia (MACINTIRE et al., 2005), além das disfunções reprodutivas como a infertilidade (SOUSA et al., 2017).

Os tumores testiculares em equinos são pouco descritos, provavelmente devido à orquiectomia realizada em equinos muito jovens, onde os testículos retirados não são enviados para análise histopatológica (SOUSA et al., 2017).

O tratamento preconizado para casos de seminomas é a orquiectomia, principalmente em quadros mais avançados. Porém, tratamentos conservativos podem ser empregados quando há diagnóstico precoce, utilizando-se técnicas de crioterapia ou quimioterapia, preservando a fertilidade do garanhão (BECK et al., 2001).

Este trabalho tem por objetivo relatar caso de equino, macho de 13 anos de idade, da raça Mangalarga Machador diagnosticado com seminoma.

\section{Relato de Caso}


Um equino da raça Mangalarga Machador, 13 anos de idade, localizado no município de Paraíba do Sul, estado do Rio de Janeiro (Lat 22016’38” S, Long 43019'59"O) apresentou aumento de massa testicular, unilateral direita, sendo relatada pelo proprietário a ocorrência de tumor testicular no histórico familiar do equino. Ao exame físico foi possível observar o testículo direito em formato oval, posição próxima ao eixo horizontal, com consistência firme, sem dor a palpação e ausência de mobilidade. O testículo esquerdo apresentava consistência ligeiramente reduzida a normal (figura $1, \mathrm{~A}$ e B) 
Figura 1 A) Fotomacrografia dos testículos evidenciando aumento do testículo direito. B) Fotomacrografia evidenciando assimetria dos testículos. C) Imagem ultrassonográfica na massa encontrada no testículo direito. Fonte: Arquivo pessoal.

O animal apresentava libido normal, ejaculado com volume de $45 \mathrm{~mL}$ (livre de fração gel), coloração esbranquiçada, consistência leitosa, odor suis generis, motilidade total de aproximadamente $60 \%$ e vigor 3 (escala 0 a 5). Os parâmetros espermáticos foram avaliados subjetivamente em microscopia óptica em aumento de 10x e considerados dentro do limite aceitável para espécie, de acordo com o Manual de Andrologia do Colégio Brasileiro de Reprodução Animal (CBRA, 2013).

Foi realizado exame ultrassonográfico das gônadas que evidenciou a presença de uma massa de aspecto heterogêneo de aproximadamente $20 \mathrm{~mm}$ de diâmetro no testículo direito (figura 1, C). O exame de ultrassonográfico das glândulas anexas não evidenciou alterações.

Foi realizada a coleta de sangue para dosagem para realização de hemograma, perfil renal e hepático, além da dosagem do hormônio Antimulleriano. Os exames hematológicos e bioquímicos não revelaram alterações. A concentração hormonal identificada foi 21,6 ng/mL, dentro do parâmetro aceitável para espécie (>0,15 ng/mL). Este resultado demonstrou haver tecido testicular funcional. A dosagem hormonal foi reali- 
zada no Laboratório de Endocrinologia da Universidade de Davis (EUA), através de radioimunoensaio.

Considerando que o animal em questão não apresentava interesse reprodutivo ao proprietário, optou-se pela orquiectomia bilateral como tratamento. Os testículos foram acondicionados em solução de formol a $10 \%$ (v/v) sob refrigeração e submetidos a análise histopatológica. 
Macroscopicamente, o testículo direito media cerca de 14 x 11 x 9 cm com superfície irregular ao corte e áreas amareladas e esbranquiçadas entremeadas por outras avermelhadas; enquanto o testículo esquerdo media cerca de $8 \times 6 \times 4,5 \mathrm{~cm}$, apresentava-se amolecido, amarronzado ao corte e com área hemorrágica central. Microscopicamente, foi observada proliferação de grandes células arredondadas ou poliédricas, com núcleos redondos, com nucléolos evidentes e volumoso citoplasma eosinofílico. Presença de algumas células neoplásicas multinucleadas, com frequentes figuras de mitos e áreas de hemorragia. De acordo com as alterações apresentadas no exame clínico, ultrassonográfico e laboratorial, o diagnóstico foi seminoma.

\section{Discussão}

Snider (2015) afirma que o seminoma geralmente é associado a dor. Entretanto, o animal do presente relato de caso não apresentava sinais compatíveis com dor à palpação de nenhum dos dois testículos, apesar das dimensões assumidas pela gônada acometida.

Na literatura, não há consenso sobre o criptorquidismo como fator predisponente. Snider (2015) aponta-o como fator de risco. Entretanto, Schumacher (2009) e Valentine (2009) afirmam que sua influência não está bem estabelecida para o desenvolvimento do seminoma. O equino do presente trabalho não apresentava criptorquidismo.

Lange et al. (2015) afirmam que o seminoma em equinos apresenta maior potencial de metástase que os demais turmores. No animal do presente relato, não houve 
sinais de metástase, como evidenciado pelo exame clínico prévio e exames hematológicos e bioquímicos realizados.

\section{Conclusão}

Os seminomas são neoplasias benignas encontradas geralmente em garanhões idosos ( $\geq 10$ anos), não produtores de hormônio e que no animal do presente relato não afetou seus parâmetros clínicos. 


\section{Agradecimentos}

Ao Hotel Fazenda Jatahy por disponibilizar seu espaço para coleta dos materiais e a Médica Veterinária Dra Luiza Barreto por colaborar durante este período.

\section{Referências}

BECK C, CHARLES JA, MACLEAN AA. Ultrasound appearance of an equine testicular seminoma. Vet Radiol Ultrasound 42:355-357. 2001.

CBRA. Manual de Andrologia do Colégio Brasileiro de Reprodução Animal. 3ed. Belo Horizonte. 2013

MACINTIRE D.K.; FERREIRA, LF,; VIANNA R.A. Emergências reprodutivas. In: Rabelo RC, Crowe Jr DT (eds) Fundamentos de terapia intensiva veterinária em pequenos animais condutas no paciente critico. L.F. Livros de Veterinária, Rio de Janeiro, pp. 397407. 2005 .

SCHUMACHER, J. Testicular neoplasia of horses: an underreported condition. $E q^{-}$ uine Vet J 31, 270-272, 1999.

SNIDER, Timothy A. Reproductive disorders in horses. Veterinary Clinics: Equine Practice, v. 31, n. 2, p. 389-405, 2015.

SOUSA, F.E.M.R. et al. Seminoma difuso em equino-relato de caso. Revista Acadêmica: Ciência Animal, v. 15, n. 1, p. 369-370, 2017.

VALENTINE, B.A. Equine testicular tumours. Equine Vet Educ 21, 177-178, 2009. 